\title{
Induction technique of sporulation in vitro of Cercospora beticola
}

\author{
Leandro Luiz Marcuzzo ${ }^{1}$, Roberto Haveroth ${ }^{1}$, Aline Nascimento ${ }^{1}$
}

${ }^{1}$ Instituto Federal Catarinense - IFC/Campus Rio do Sul, CP 441, CEP 89.163-356, Rio do Sul, SC.

Author for correspondence: Leandro Luiz Marcuzzo (marcuzzo@ifc-riodosul.edu.br)

Data de chegada: 16/10/2014. Aceito para publicação em: 19/12/2014.

$10.1590 / 0100-5405 / 2054$

Cercospora beticola (Sacc.) is an etiologic agent of cercospora leaf spot on beet, which is characterized as the main disease of beet crop. Laboratory assignments require a purified organism with expressive sporulation. After the monosporic isolation of $C$. Beticola, a disc with micelles $(9 \mathrm{~mm})$ was replicated in a tomato extract growth medium ( $200 \mathrm{~g}$ of tomato extract $3 \mathrm{~g}$ of $\mathrm{CaCO}_{3}, 20 \mathrm{~g}$ of agar and $1000 \mathrm{ml}$ of distillate water). The mycelium growth needed more than 20 days to cover the entire dish Petri $(80 \times 12 \mathrm{~mm})$ in incubation at $25^{\circ} \mathrm{C}$ and with a photoperiod of 12 hours. From the mycelium growth there was removed a piece of approximately $2 \times 2$ $\mathrm{cm}$ using a scalpel. Then the fragment of mycelium cut was scrubbed on the tomato extract growth medium by using a histological needle
(Figure 1A). The same mycelium cut was scrubbed over the entire Petri dish. Residues of mycelium or fragment of growth medium were removed from the surface by using a scalpel. The growth medium was incubated at $25^{\circ} \mathrm{C}$ and with a photoperiod of 12 hours. The growth medium produced in average $1 \times 10^{4}$ spores $\mathrm{ml}^{-1}$ placa ${ }^{-1}$. The sporulation started after the fourth day. The mycelium growth was maintained and evaluated after seven days of incubation (Figure 1B), reducing the sporulation after this period. This methodology has been used to conduct research with $C$. beticola in the laboratory of Phytopathology at the Federal Institute Catarinense/Campus Rio do Sul. This technique can be evaluated for induction of sporulation in other species of Cercospora.
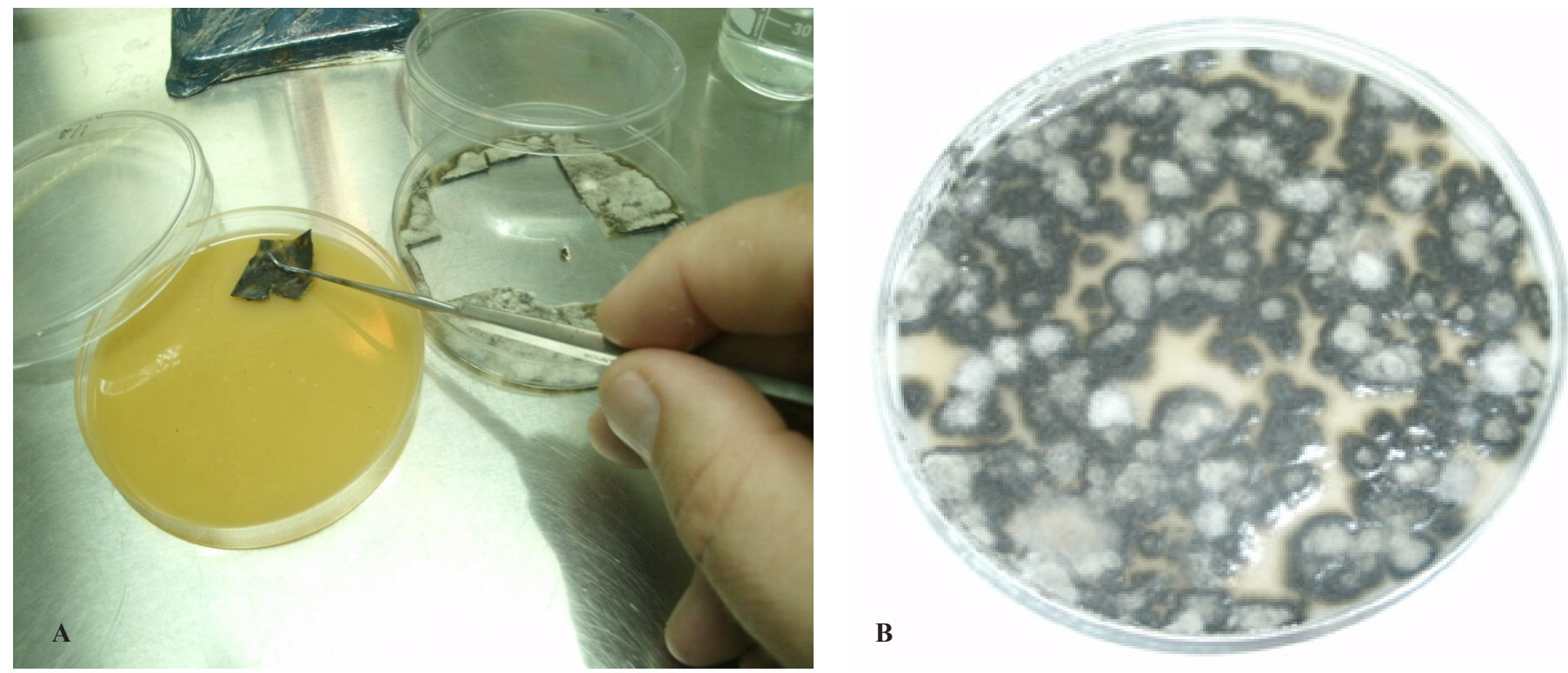

Figure 1. Scrubbed of mycelium growth in the tomato extract growth medium by using a histological needle (A) The mycelium development after seven days of incubation (B). 